\title{
Intravenous Immunoglobulins: In-Depth Review of Excipients and Acute Kidney Injury Risk
}

\author{
Jacques Dantal
}

Institut de Transplantation Urologie Néphrologie (ITUN) and INSERM U643, CHU Hôtel Dieu, Nantes, France

\section{Key Words \\ Intravenous immunoglobulins . Adverse drug reactions . \\ Side effects · Renal failure · Acute kidney injury}

\begin{abstract}
Background: Used in a variety of approved and off-label indications, there are several intravenous immunoglobulin (IVIG) preparations available which differ in the excipients (e.g. sucrose, glucose, maltose, D-sorbitol, glycine or L-proline) used to stabilize the protein in the solution. A very rare, but severe adverse drug reaction (ADR) reported with sucrose-stabilized IVIGs, acute renal failure, is well established, but the relative risks with sucrose-free IVIGs are unknown. Methods: Medline and Embase were searched for published data on ADRs involving the kidney, and DrugCite, a public database of $>4,000,000$ ADRs from the USA, was also searched. Renal impairment-associated ADRs and categories were summarized. Results: Compared with sucrose-containing IVIGs, reports of ADRs involving the kidney were relatively rare with sucrose-free IVIGs: 12 cases were published prior to February 28, 2012; incidences reported in DrugCite were also relatively low and similar among sucrose-free preparations. The incidence of hemolysis-related ADRs, a potential cause of secondary acute renal impairment, was higher with glycine- and L-proline-stabilized IVIGs. Reported incidences of renal impairment with sucrose-free IVIGs are
\end{abstract}

similar between products and much lower than with sucrose-stabilized IVIGs. Conclusions: It is recommended that the choice of IVIG should be guided by the patient's medical history, present comorbidities and concomitant medications. Prospective studies with inclusion of creatinine values, as well as rigorous reporting of cases in the literature and/or via pharmacovigilance systems, are imperative to better define patient profiles.

Copyright $\odot 2013$ S. Karger AG, Basel

\section{Background}

Intravenous immunoglobulins (IVIGs) are used in a variety of approved and off-label indications [1, 2]. US Food and Drug Administration (FDA)- and European Medicines Agency (EMA)-approved indications include: treatment of primary immunodeficiency disorders, prevention and control of bleeding in idiopathic thrombocytopenic purpura, prevention of coronary artery aneurysms in Kawasaki disease, chronic inflammatory demyelinating polyneuropathy and prevention of infection in chronic B-cell lymphocytic leukemia. Off-label uses include neurologic and dermatologic disorders, solid-organ transplantation, selected secondary immunodeficiencies and autoimmune diseases, and infectious and infection-related diseases [3-5]. Over 150 off-label uses

\section{KARGER}

E-Mail karger@karger.com

www.karger.com/ajn (c) 2013 S. Karger AG, Basel

0250-8095/13/0384-0275\$38.00/0
Prof. Jacques Dantal

INSERM U643, CHU Hôtel Dieu

30 Bd Jean Monnet

FR-44093 Nantes (France)

E-Mail jacques.dantal@chu-nantes.fr 
have been identified, the majority from case reports and uncontrolled studies [3].

In several countries, the clinical use of IVIG is directed not only by the approved indication described in the Marketing Authorization, but also by national guidelines, e.g. in the UK [6] or France [7], or expert consensus, e.g. in Canada [8,9] or Australia [10].

IVIGs are generally well tolerated. The majority of adverse drug reactions (ADRs) are mild in severity, reversible by slowing or temporarily stopping the infusion, and often occur during or after one of the first infusions of an IVIG product $[4,11]$. Most commonly reported ADRs include headaches, back or abdominal pain, nausea/vomiting, rhinitis, asthma, fever, chills and myalgias. Serious ADRs occur more rarely and include thromboembolic events, hemolysis and hemolytic anemia, and renal failure associated with stabilizers $[4,11]$.

Stabilizers are used in IVIG preparations to prevent formation of dimers and polymers, which were thought to be responsible for many of the ADRs reported with IVIG formulations, such as chills, fever, fatigue, and chest, hip, joint and back pain $[12,13]$. Stabilizers used in IVIG preparations include sucrose, glucose, maltose, Dsorbitol, mannitol, glycine and L-proline (table 1).

Renal impairment related to IVIGs stabilized with sucrose (e.g. Tegeline ${ }^{\circledR}$; Carimune $\mathrm{NF}^{\circledR} /$ Sandoglobulin ${ }^{\circledR}$ ), including acute renal failure, osmotic nephrosis and renal insufficiency, is well established. Many case reports and several review articles have been published and nephrotoxicological mechanisms defined. Since the kidneys do not express sucrase, sucrose administered intravenously cannot be metabolized, accumulating in the proximal tubules and causing hyperosmolality which leads to renal injury [13-16]. Sucrose causes renal injury as it enters tubular epithelial cells via pinocytosis. Incorporation of sucrose into lysosomes causes swelling of epithelial cells and cytoplasmic vacuolization of the tubules, especially in the proximal tubules. Swelling and vacuolization causes narrowing of the tubular lumina, leading to injury and degeneration of the proximal tubular epithelium.

IVIG-associated renal failure mostly occurs in patients with preexisting conditions or those at increased risk for renal ADRs, such as prior renal insufficiency, diabetes mellitus, elderly ( $>65$ years old), volume depletion (dehydration or hypervolemia), sepsis, paraproteinemia or concomitant use of other agents known to cause renal toxicity [17-19]. The incidence of renal failure with IVIGs stabilized with glucose, maltose, D-sorbitol, mannitol, glycine or L-proline is lower than with sucrose-stabilized products; 79 of 88 cases of renal ADRs reported in the USA between June 1985 and November 1998 were in patients who received sucrose-stabilized IVIGs [20, 21] and of 34 hemodialysis cases recorded by the FDA Adverse Event Reporting System (AERS) between 2004 and 2009 , the excipient was known in 28 cases and all but 1 consisted of sucrose [22], despite an estimated relative increased usage of sucrose-free IVIGs [23-25].

The incidence of renal failure associated with sucrosefree products is perceived to be similar among agents, but the relative risk of renal impairment is unknown. This review discusses the relative risk of renal failure and other renal impairment with IVIG products stabilized with sucrose, glucose, maltose, D-sorbitol, mannitol, glycine and L-proline. In addition, possible mechanisms for the reported nephrotoxicity are explored and clinical recommendations made.

\section{Search}

Medline and Embase were searched for published data (case reports, retrospective database analyses, review articles) using the following search terms: (immunoglobulins, immunoglobulin therapy, IVIG therapy, immune globulin, OR gammaglobulin) AND (osmotic nephrosis, acute renal failure, osmotic nephropathy, nephrotoxicity, anuric renal failure, renal impairment, vacuolization, kidney failure, renal insufficiency, glomerulonephritis, renal toxicity, adverse events, safety, nephritis, acute kidney injury OR renal dysfunction), no search dates specified, limited to human studies, English-language articles only. Search results were filtered to identify relevant papers. In addition, communications from the Agence $\mathrm{Na}$ tionale de Sécurité du Médicament et des Produits de Santé (ANSM, formerly AFSSAPS) were included [26], as well as any other relevant non-English language articles and papers identified from the bibliographies of relevant publications.

As several papers have published FDA-reported incidences of IVIG-induced renal failure [20-22], the FDA database (www.drugcite.com) was also searched. At the time of writing, it was not possible to access European data since the EMA did not have a publically available pharmacovigilance system. However, recently the EMA decided to make European safety data available to the general public (www.adrreports.eu), but only for products registered via the EMA-centralized European Marketing Authorization procedure. Since most IVIG products are registered by other authorities, their ADRs will not be listed in this website.

DrugCite is a public database of more than 4,000,000 ADRs reported to the US FDA by clinicians, healthcare 
Table 1. Product characteristics and registered indications of the available IVIGs $[1,2,4,19,22,78-82]$

\begin{tabular}{|c|c|c|c|c|c|c|c|c|}
\hline Brand name(s) (manufacturer) & Form & $\begin{array}{l}\text { Sugar } \\
\text { content, } \\
\mathrm{mg} / \mathrm{ml}\end{array}$ & $\begin{array}{l}\text { Maximum } \\
\text { infusion rate, } \\
\mathrm{ml} / \mathrm{kg} / \mathrm{min}\end{array}$ & $\mathrm{pH}$ & $\begin{array}{l}\text { Osmolarity/ } \\
\text { osmolality, } \\
\text { mosm/l }\end{array}$ & $\begin{array}{l}\text { US FDA- } \\
\text { approved } \\
\text { indications }\end{array}$ & $\begin{array}{l}\text { EU-marketed } \\
\text { indications }\end{array}$ & $\begin{array}{l}\text { Date first } \\
\text { registered } \\
\text { (country) }\end{array}$ \\
\hline $\begin{array}{l}\text { Sucrose-stabilized IVIGs } \\
\text { Carimune NF 3, 6, } 9 \text { and 12\% } \\
\text { (identical to Sandoglobulin; } \\
\text { CSL Behring) }\end{array}$ & $\begin{array}{l}\text { lyophilized } \\
\text { powder }\end{array}$ & $1.67^{\mathrm{a}}$ & $3^{\mathrm{b}}$ & $6.4-6.8$ & $\begin{array}{l}192(3 \%), \\
384(6 \%), \\
576(9 \%), \\
768(12 \%)\end{array}$ & ITP, PID & NA & $\begin{array}{l}\text { Jun } 1984 \\
\text { (US) }\end{array}$ \\
\hline $\begin{array}{l}\text { Glucose-stabilized IVIGs } \\
\text { Endobulin } \mathrm{S} / \mathrm{D}^{\mathrm{c}} \\
\text { (Baxter) }\end{array}$ & $\begin{array}{l}\text { lyophilized } \\
\text { powder }\end{array}$ & 50 & NR & $6.4-7.2$ & $\geq 240$ & KS, PID & NA & $\begin{array}{l}\text { Feb } 1986 \\
\text { (US) }\end{array}$ \\
\hline $\begin{array}{l}\text { Maltose-stabilized IVIGs } \\
\text { Octagam } 5 \text { and } 10 \% \\
\text { (Octapharma) }\end{array}$ & liquid & 100 & 0.07 & $5.1-6.0$ & $310-380$ & PID & $\begin{array}{l}\text { AGG, AI disorders, GBS, } \\
\text { GVHD, ID, ITP, MLNS }\end{array}$ & $\begin{array}{l}\text { Feb } 1995 \\
\text { (Germany) } \\
\text { May 2004 } \\
\text { (USA) } \\
\text { May 2008 } \\
\text { (EU) }\end{array}$ \\
\hline $\begin{array}{l}\text { D-Sorbitol-stabilized IVIGs } \\
\text { Flebogamma DIF } 5 \\
\text { and } 10 \% \\
\text { (Grifols) }\end{array}$ & liquid & 50 & $\begin{array}{l}0.1(5 \%) \\
\text { and } \\
0.08(10 \%)\end{array}$ & $5.0-6.0$ & $240-370$ & PID & GBS, ID, ITP & $\begin{array}{l}\text { Dec } 2003 \\
\text { (USA) } \\
\text { Aug } 2007 \\
\text { (EU) }\end{array}$ \\
\hline $\begin{array}{l}\text { Gammaplex } 5 \%^{c} \\
\text { (Bio Products Laboratory) }\end{array}$ & liquid & 50 & 0.08 & $4.8-5.0$ & $420-500$ & PID & NA & $\begin{array}{l}\text { Sep } 2009 \\
\text { (USA) }\end{array}$ \\
\hline $\begin{array}{l}\text { Mannitol-stabilized IVIGs } \\
\text { Clairyg 5\% } \\
\text { (LFB Biomedicaments) }\end{array}$ & liquid & 32 & NA & NA & NA & NA & ID, PID & $\begin{array}{l}\text { Dec 2009 } \\
\text { (France) }\end{array}$ \\
\hline $\begin{array}{l}\text { Gamunex-C } 10 \% \\
\text { (Talecris Biotherapeutics) }\end{array}$ & liquid & none & 0.08 & $4.0-4.5$ & 258 & $\begin{array}{l}\text { CIDP, } \\
\text { ITP, } \\
\text { PID }\end{array}$ & CIDP, ID, ITP, MS & $\begin{array}{l}\text { Aug } 2003 \\
\text { (USA) } \\
\text { Mar 2004 } \\
\text { (EU) }\end{array}$ \\
\hline $\begin{array}{l}\text { Gammaked 10\% } \\
\text { (Kedrion Biopharma) }\end{array}$ & liquid & none & 0.08 & $4.0-4.5$ & 258 & $\begin{array}{l}\text { CIDP, } \\
\text { ITP, PI }\end{array}$ & NA & $\begin{array}{l}\text { Aug } 2011 \\
\text { (USA) }\end{array}$ \\
\hline $\begin{array}{l}\text { L-Proline-stabilized IVIGs } \\
\text { Privigen } 10 \% \\
\text { (CSL Behring) }\end{array}$ & liquid & none & 0.08 & $4.6-5.0$ & $240-440$ & ITP, PID & $\begin{array}{l}\text { CIDP, CLL, HIV } \\
\text { (pediatric), ITP, KS, PID }\end{array}$ & $\begin{array}{l}\text { Jul } 2007 \\
\text { (USA) } \\
\text { Apr } 2008 \\
(\text { EU) }\end{array}$ \\
\hline
\end{tabular}

\footnotetext{
${ }^{a}$ Sugar content given as g sucrose per g of protein. ${ }^{\mathrm{b}}$ Infusion rate given as $\mathrm{ml} / \mathrm{kg} / \mathrm{h} .{ }^{\mathrm{c}}$ Endobulin SD and Gammaplex $5 \%$ also contain glycine. ${ }^{\mathrm{d}}$ Gammagard SD also contains $2 \%$ glucose.

AGG = Agammaglobulinemia; $\mathrm{AI}=$ autoimmune; $\mathrm{BMT}=$ bone marrow transplantation; $\mathrm{BSRC}=$ birdshot retinochoroidopathy $\mathrm{CIDP}=$ chronic inflam matory demyelinating polyneuropathy; CLL = chronic lymphocytic leukemia; GBS = Guillain-Barré syndrome; GVHD = graft-versus-host disease; HIV = human immunodeficiency virus infection; ID = immunodeficiency disorders; ITP = idiopathic thrombocytopenic purpura; KS = Kawasaki syndrome; MLNS = mucocutaneous lymph node syndrome; $\mathrm{MMN}=$ multifocal motor neuropathy; $\mathrm{MS}=$ multiple sclerosis; $\mathrm{NA}=$ not applicable; $\mathrm{NR}=$ not reported $\mathrm{PID}=$ primary immunodeficiency disorder.
} 


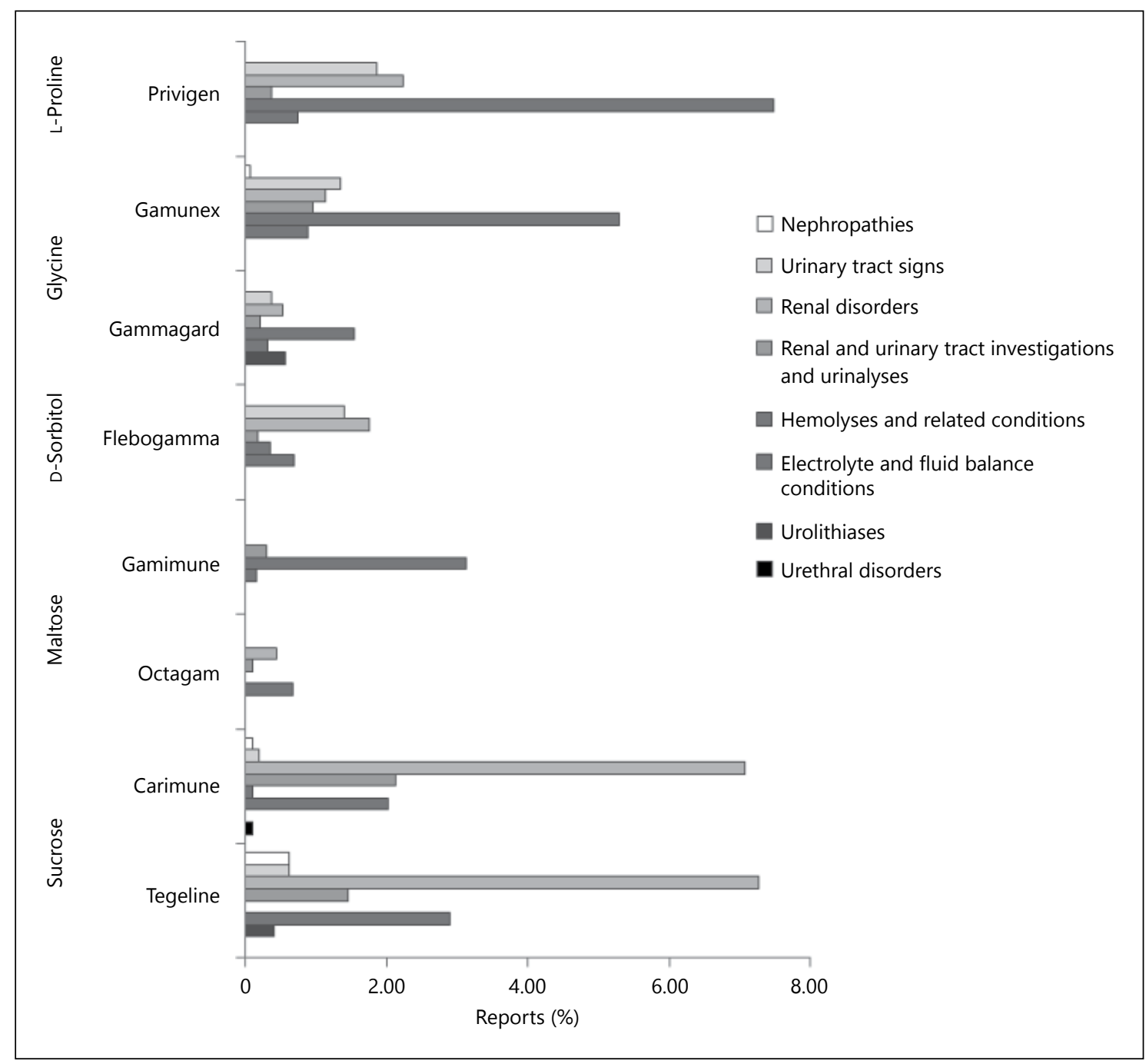

Fig. 1. Selected ADRs reported in the DrugCite database (www. drugcite.com/) for IVIG products. Renal impairment-associated ADR categories submitted to the FDA for each agent, as well as related generic and/or brand name drugs containing the same pri- mary active ingredients, from Q1 2004 to Q2 2011 (except for Flebogamma and Privigen for which data were only available from Q1 2007 and Q3 2008, respectively). ADRs are counted if the agent is flagged as a suspect drug causing the ADR. consumers, lawyers and others, via their AERS. Submitted ADRs are subsequently assessed by FDA scientific staff to determine if the safety concern is associated, and possibly caused by, exposure to a specific drug. All renal impairment-associated categories and ADRs (see table 2 and figure 1 for specific terms) reported up to 28 February 2012 were extracted and summarized. Drug names searched were: tegeline, carimune/carimune NF, endobulin, octagam, gamimune/gamimune $\mathrm{N} /$ gamimune $\mathrm{N} 5 /$ gamimune $\mathrm{N} 10$, polyglobin $\mathrm{N}$ (gamimune), gammaplex, flebogamma/flebogamma 5\% DIF, gammagard/gammagard S/D/gammagard, liquid/Kiovig, gam- maked, gamunex, privigen, clairyg, gammonativ, IVI Glob EX, intagam P and other variations thereof. Cases accessible in DrugCite may also be published in the literature; therefore, these data were reviewed separately from published case reports.

\section{Results}

Product characteristics and registered indications of sucrose-free IVIG products available in the USA and/or Europe are presented in table 1. 
Table 2. Selected most common ADRs reported in the DrugCite database (www.drugcite.com/) for IVIG products

\begin{tabular}{|c|c|c|c|c|c|c|c|c|}
\hline ADR & Tegeline & Carimune & Octagam & Gamimune & $\frac{\text { D-Sorbitol }}{\text { Flebogamma }^{\mathrm{a}}}$ & Gammagard & Gamunex & $\frac{\text { L-Proline }}{\text { Privigen }^{b}}$ \\
\hline Anuria & $2(0.41)$ & $7(0.68)$ & & & & & & $2(0.37)$ \\
\hline Blood creatinine increased & $4(0.83)$ & $17(1.65)$ & & & & & & \\
\hline Calculus urinary & $2(0.41)$ & & & & & & & \\
\hline Hyponatremia & $7(1.45)$ & $7(0.68)$ & & & & & & \\
\hline Kidney transplant rejection & & & & & & & & $2(0.37)$ \\
\hline Oliguria & & $14(1.36)$ & & & & & & \\
\hline Renal failure & $4(0.83)$ & $17(1.65)$ & & & & $20(0.21)$ & $24(0.56)$ & $6(1.12)$ \\
\hline Renal failure acute & $24(4.98)$ & $32(3.1)$ & & & $9(1.58)$ & & $18(0.42)$ & \\
\hline \multicolumn{9}{|c|}{ Hemolysis-associated adverse events } \\
\hline Chromaturia & & & & & & & $11(0.26)$ & $4(0.75)$ \\
\hline Coombs direct test positive & & & & & & & $40(0.93)$ & $4(0.75)$ \\
\hline Hematuria & & & & & $8(1.40)$ & & $17(0.39)$ & \\
\hline Hemoglobinuria & & & & & & & $21(0.49)$ & $6(1.12)$ \\
\hline Hemolysis & & & & $9(1.34)$ & & $96(1.01)$ & $120(2.79)$ & $13(2.43)$ \\
\hline Hemolytic anemia & & & & $12(1.79)$ & $2(0.35)$ & $44(0.46)$ & $98(2.27)$ & $14(2.62)$ \\
\hline
\end{tabular}

Values in parentheses are percentages.

Renal impairment-associated ADRs submitted to the FDA for each agent, as well as related generic and/or brand-name drugs containing the same primary active ingredients from Q1 2004 to Q2 2011. ADRs are counted if the agent is flagged as a suspect drug causing the ADR. The terms used to describe the ADRs are those used in the declaration.

a Data on adverse events were only available from Q1 2007. ${ }^{\mathrm{b}}$ Data on adverse events were only available from Q3 2008.

\section{Case Reports}

In general, reports of renal impairment with sucrosefree IVIGs are relatively rare, and there are several cases reported where patients tolerated glucose- [27], maltose[28-32], D-sorbitol- [15], and glycine-stabilized IVIGs $[12,33,34]$, but developed acute renal failure with sucrose-containing IVIGs in previous or subsequent treatments.

Of the published case reports of renal impairment and/or renal failure with sucrose-free IVIGs (or unknown excipient), there are no published case reports with glucose-containing IVIGs, but eight with maltose [35-42]. These IVIGs included several products, most commonly Gamimune/Polyglobin N $(\mathrm{n}=2)[40,42]$, Intragam $(\mathrm{n}=2)[37,38]$, and Octagam $(\mathrm{n}=2)[36,39]$. Most cases had known risk factors for renal failure, such as diabetes mellitus $[35,37,39]$ and preexisting renal dysfunction $[35,41,42]$.

IVIG Stabilizers and Renal Function
Acute tubulointerstitial nephritis was reported in 1 patient after receiving mannitol-containing IVIG [43]. The 4-year-old boy was being treated for a third relapse of nephrotic syndrome and, interestingly, was also receiving furosemide, which has been suggested to play a synergistic role in the development of osmotic nephrosis when used with mannitol in other indications $[44,45]$. Three cases treated with D-sorbitol, glycine and L-proline (1 patient each) also had known risk factors for renal failure, including renal dysfunction, as well as comorbidities such as hypertension, severe thrombocytopenia and chronic graftversus-host disease [46-48]. The case involving L-proline as the excipient, also reported hemoglobinuria linked to hemolysis [48]. The excipient was unknown in 7 cases [49-54] and, although some patients had preexisting renal insufficiency, there were no other outstanding features. Details of several of these, however, indicate that in some, sucrose-containing IVIGs were used [49, 51-53]. 


\section{Other Published Studies}

A retrospective study utilizing histologic examination of systematic serial biopsy specimens from kidney transplant recipients with high immunological risk revealed tubular macrovacuoles in 17 of 27 (63\%) patients following treatment with glucose- (Endobulin) and/or maltose(Octagam) containing IVIGs, compared with none of 27 control patients not receiving IVIG [55]. These results were obtained despite an absence of acute renal failure in the cohort. Analysis of risk factors associated with the presence of macrovacuoles in the IVIG-treated patients showed that macrovacuoles were more frequent in kidneys from older donors (mean 51.4 vs. 38.0 years; $\mathrm{p}=$ 0.003 ). Despite similar histologic findings pre-transplantation, subtle age-related tubular impairment, making them more vulnerable to IVIG-related toxicity, was present in the donor grafts of transplant patients that developed macrovacuoles.

An ANSM-conducted search of the Database National Pharmacovigilance revealed 91 cases of renal failure reported to the Regional Centre for Pharmacovigilance (CRPV) between 1999 and 2005 [26], the majority with sucrose-stabilized products Tegeline $(\mathrm{n}=84)$ and Sandoglobulin $(n=6)$. Only 1 case was reported with sucrosefree IVIGs (Gammagard) and no cases with Endobulin or Octagam. Previously defined risk factors were concomitant administration of potentially nephrotoxic drugs (loop diuretics, angiotensin-converting enzyme inhibitors, angiotensin receptor antagonists, cyclosporine, iodinated contrast agent, aminoglycosides, vancomycin), prior renal impairment, diabetes, hypertension, hypovolemia and obesity.

\section{DrugCite Data}

Selected renal impairment-associated ADR categories and ADRs submitted to the FDA and reported in the DrugCite database are shown in figure 1 and table 2, respectively. During the search process, there were no hits for endobulin, polyglobin N, gammaplex, gammaked, clairyg, gammonativ, IVI Glob EX or Intragam P, most likely because they are not licensed in the USA, although, interestingly, ADRs are reported for Tegeline, which is also not licensed there. Renal failure (chronic and acute) was reported with all excipients except maltose (Octagam and Gamimune) (table 2). As expected, the highest incidence was reported with sucrose-containing IVIGs (Tegeline and Carimune); renal tubular disorder and renal tubular necrosis were also reported with these products (table 2).

Hemolysis-related ADRs, a potential cause of secondary acute renal impairment (see following section), were mostly reported with glycine- (Gamunex, 5.29\% of reports) and L-proline- (Privigen, $7.48 \%$ ) stabilized IVIGs, as well as one of the maltose-stabilized products Gamimune (approx. 3.5\%) (fig. 1; table 2).

\section{Possible Mechanisms of Renal Toxicity}

Similarly to sucrose, excessive glucose accumulation can have deleterious effects on proximal kidney tubules in humans [56] and, since intravenous glucose infusion is known to produce a rapid increase in blood glucose and insulin levels in normal subjects, diabetic patients are at particular risk of renal damage following administration of glucose-stabilized IVIGs. Osmotic nephrosis caused by excessive glucose loading has been reported in both animals and humans, and 10\% glucose solutions have been demonstrated to induce osmotic nephrosis in humans [44].

On the other hand, maltose-stabilized IVIGs are likely better tolerated because maltase, the enzyme which hydrolyzes maltose to glucose, is present in the brush border of proximal convoluted renal tubules $[56,57]$. Animal experiments have demonstrated that, unlike sucrose, of which $>60 \%$ is excreted unchanged in the urine, maltose is mostly metabolized with $<5 \%$ excreted unchanged [57]. Therefore, a possible mechanism of maltose-induced nephrotoxicity may be inhibition of maltase or when tubular load is higher than the metabolic capacity of the brush border, especially in the presence of hyperglycemia when the breakdown of maltose to glucose is greatly reduced $[35,56]$.

D-Sorbitol is primarily metabolized within the liver and, to a lesser extent, in the kidneys and other tissues. Intracellular accumulation of sorbitol is finely regulated within the kidney by the complementary actions of aldose reductase and sorbitol dehydrogenase [58-60], which probably accounts for the relatively low incidence of acute renal failure with sorbitol-stabilized IVIGs [56]. Histological findings in 1 reported case of sorbitol-induced acute renal failure demonstrated not only tubular vacuolization with preservation of the brush border typical of osmotic nephrosis caused by other sugar-stabilized IVIGs, but also vacuolization in epithelial cells of the glomeruli [47].

Evidence suggests that intravenous mannitol administered with IVIGs (e.g. Clairyg ${ }^{\circledR}$ containing $3.2 \%$ of mannitol) may cause tubular damage [61], and mannitol-induced acute renal failure has been reported in other indications $[45,62,63]$. This apparent difference between the 
polyols may be because mannitol is metabolically inert, eliminated solely by the kidneys approximately $90 \%$ excreted unchanged [64], resulting in increased nephrotoxicity risk in patients with renal insufficiency. A postulated mechanism is renal vasoconstriction caused by high levels of mannitol [45] or by concomitant administration of cyclosporine A [62], with subsequent mannitol-induced osmotic nephrosis. Other proposed mechanisms include tubuloglomerular feedback in response to increased tubule fluid osmolality delivered to the macula densa or depleted intravascular volume mannitol due to osmotic diuresis $[65,66]$.

Whilst glycine and L-proline do not have a direct impact on the kidneys, a positive direct antiglobulin test, or DAT (i.e. a positive Coombs' test), may result, and acute hemolysis has been reported following amino-acid-stabilized IVIG infusion [67-71]; our data show relatively high rates of hemolysis and related conditions (fig. 1; table 2). Whilst rare, at least 1 case of pigment-mediated acute renal injury secondary to hemoglobinuria has been published with IVIGs [48]. In February 2012, the EMA announced expansion of the Summary of Product Characteristics warning for Privigen ${ }^{\circledR}$ on the risk of hemolytic anemia [70, 71]. High doses of Privigen (either as a single administration or divided over several days) and non-O blood group were identified as risk factors for hemolytic reactions based on analysis of case reports and underlying inflammatory state (based on scientific literature). It should be noted that previous studies have also shown an increased risk of IVIG-induced hemolytic anemia with the use of newer liquid IVIG preparations that are derived by column chromatography techniques [69]. This increased risk appeared to be related to the elevated concentrations of anti-A/B blood group antibodies in these highly purified products. Secondary acute renal failure was reported in 4 of 104 patients who experienced hemolytic disorders, and disseminated intravascular coagulation was reported in 2 patients. Health Canada also issued similar warnings in June 2012 [72].

\section{Discussion}

Relative to sucrose-stabilized IVIGs, the incidence of renal failure and other renal impairment reported in the literature and via the FDA MedWatch program for IVIGs stabilized with glucose, maltose, D-sorbitol, mannitol, glycine or L-proline is much lower. Acute renal failure induced by sucrose-containing IVIG is likely related to the toxic action of sucrose on the nephron, where excess sucrose in the kidney causes osmotic nephrosis. Whilst osmotic nephrosis has been reported with sucrose-free IVIG, the incidence is much lower because the levels of these agents can be closely regulated by enzymes within the kidney [35, 56-60]. Therefore, renal impairment with these other excipients is likely to be caused by different mechanisms, not yet identified, including inhibition of renal enzymes involved in excipient metabolism, renal vasoconstriction, tubuloglomerular feedback and secondary pigment-mediated acute renal injury $[35,45,48$, $56,58-60,65]$. Further research is necessary to find out if renal impairment is related to these stabilizers.

Clinically, since various components of IVIG formulations can affect patients differently depending on their medical profile, it is possible to minimize the risk of IVIG-induced adverse events by appropriate product selection. A patient's medical history and risk factors, such as age, comorbidities and contraindications, must be carefully considered alongside each product's properties to ensure selection of an appropriate IVIG product to avoid severe adverse events. It is possible to identify two distinct patient populations prior to IVIG treatment: patients at risk of developing renal failure and those who have already experienced renal failure and who require additional treatment with IVIG. Patients at risk of developing renal failure include those taking concomitant medications with the potential for renal toxicity, those with an indication for IVIG treatment with a high risk of renal toxicity, such as renal graft, and those with impaired renal function (glomerular filtration rate and serum creatinine assessed). Older patients require special consideration, since they appear to be at particular risk of acute renal failure [73].

Several precautionary measures have been suggested both by healthcare authorities and clinical experts. For patients with a history of renal impairment, or risk factors, the following points should be taken into consideration:

(1) Consider using the lowest effective dose, especially in chronically treated patients, such as those with neurological indications.

(2) Dose and infusion speed should be kept low. Depending on the clinical indication, IVIGs are used with various administration schemas, but the amount of IVIG infused daily can be decreased by increasing infusion frequency.

(3) Another interesting alternative to dose fractionation is the use of subcutaneous immunoglobulin products (SCIGs). Indeed, the daily infused quantity is much 
lower with SCIGs than with IVIGs; for example, for primary immunodeficiency disorders, IVIG $30 \mathrm{~g}$ /day once a month is used, or SCIGs $7.5 \mathrm{~g} /$ day once a week. Moreover, the pharmacokinetic profile of SCIG is different compared with IVIG, insuring a slower increase of peak IgG quantity in blood $[74,75]$.

(4) Hydration is widely recommended in patients at risk of renal failure; however, it is important that volume overloading complications (e.g. congestive heart failure) are avoided.

(5) US FDA recommends infusion rate reduction and dose fractionation, to decrease the possible nephrotoxic action of IVIG protein molecules and stabilizers.

(6) Renal function assessment (i.e. urine output, serum creatinine levels) should be done, before first IVIG administration and during treatment, at appropriate intervals, depending on the dose of IVIG administered.

(7) Some concomitant medications should be avoided in patients receiving IVIG infusions, e.g. inhibitors of the renin-angiotensin system [18, 76, 77]. Generally, re-assess all prescribed drugs, especially in elderly patients.

All these recommendations are based on clinical experience and expert opinion only since, unfortunately, no prospective clinical data are presently available to identify real risk factors or efficient precautionary measures. There is a need for new clinical studies investigating the safety of IVIGs, taking into account not only data from prospective development studies in small populations (as usually done for pivotal studies to obtain a new Marketing Authorization), but also observational studies, registries and other post-authorization trials.

Limitations of the current study are mostly related to use of DrugCite data. Firstly, there is a lack of homogeneity in the definitions used to describe this particular ADR (e.g. renal failure, acute renal failure, chronic renal failure, oliguria, anuria), especially since they are collected from healthcare professionals and the general public. Also, since ADR annual rates are not given and the relative usage of the individual preparations is unknown, DrugCite data interpretation is difficult. Reported ADR incidence does not correlate with perfusion number or cumulated IVIG dose over the time period. Also, since the US FDA does not require that a causal relationship between a product and event be proven, it is uncertain whether a DrugCite-reported event is due to the product, i.e. a true ADR; often, reports do not contain enough detail to evaluate an event properly. Finally, not all ADRs are reported to the database and many factors influence whether or not an event is re- ported, such as time on the market or media publicity causing a flurry of reporting a particular adverse event. This combination of factors means that using DrugCite data to calculate ADR incidence in the US population is not feasible.

Since only declarative data and prospective series are available, thus limiting any definitive conclusions, future directions should include prospective studies (according to patients' profiles and IVIG indications) and the scoring of ADRs. Ideally, prospective randomized, controlled trial data are needed, but the large number of patients required to detect this rare ADR makes this impractical and unrealistic. However, inclusion of prospectively measured creatinine values into protocols of all future investigator studies is simple and possible. In the absence of such data in the meantime, the heavy reliance on pharmacovigilance reporting means it is imperative that physicians publish and/or report all cases of renal impairment with these products to better define patient profiles.

\section{Conclusions}

The incidence of IVIG-related impairment of renal function cannot be determined, but the number of reported cases suggests a significantly lower incidence for preparations containing stabilizers other than sucrose. The small number of reports leads us to assume a similar incidence among sucrose-free IVIGs. However, there seems to be increased reporting of renal failure secondary to hemolysis caused by some amino acid-based IVIGs. Nevertheless, with respect to renal impairment risk, all sucrose-free IVIGs might be considered equivalent and choice should be guided by the patient's medical history, present comorbidities and concomitant medications.

\section{Acknowledgments}

Medical writing assistance was provided by Mary Hines and Andrea Bothwell of inScience Communications, Springer Healthcare, and funded by Octapharma AG, Switzerland. Octapharma provided revisions to the manuscript.

\section{Disclosure Statement}

J.D. has received honorarium from LFB, Novartis and Astellas Pharma. 


\section{References}

1 Mark SM: Comparison of intravenous immunoglobulin formulations: product, formulary, and cost considerations. Hosp Pharm 2011; 46:668-679.

2 Siegel J: Immune globulins: therapeutic, pharmaceutical, cost, and administration considerations. Pharmacy Practice News, Special Edition, October 2011.

-3 Leong H, Stachnik J, Bonk ME, Matuszewski KA: Unlabeled uses of intravenous immune globulin. Am J Health Syst Pharm 2008;65: 1815-1824.

4 Orange JS, Hossny EM, Weiler CR, et al: Use of intravenous immunoglobulin in human disease: a review of evidence by members of the Primary Immunodeficiency Committee of the American Academy of Allergy, Asthma and Immunology. J Allergy Clin Immunol 2006;117(suppl):S525-S553.

$>5$ Ratko TA, Burnett DA, Foulke GE, Matuszewski KA, Sacher RA: Recommendations for off-label use of intravenously administered immunoglobulin preparations. University Hospital Consortium Expert Panel for OffLabel Use of Polyvalent Intravenously Administered Immunoglobulin Preparations. JAMA 1995;273:1865-1870.

6 Wimperis J, Lunn M, Jones A, et al: Clinical guidelines for immunoglobulin use. Second edition update. 2011. http://www.dh.gov.uk/ prod_consum_dh/groups/dh_digitalassets/ documents/digitalasset/dh_131107.pdf (accessed September 21, 2012).

7 Agence Nationale de Sécurité du Médicament et des Produits de Santé: Octagam $100 \mathrm{mg} / \mathrm{ml}$, solution pour perfusion. http://ansm.sante.fr/ Dossiers-thematiques/Referentiels-de-bonusage-des-medicaments/Immunoglobulines/ Tableau-immunoglobulines/OCTAGAM100-mg-ml-solution-pour-perfusion (accessed September 21, 2012).

$>8$ Anderson D, Ali K, Blanchette V, et al: Guidelines on the use of intravenous immune globulin for hematologic conditions. Transfus Med Rev 2007;21(suppl 1):S9-S56.

$>9$ Feasby T, Banwell B, Benstead T, et al: Guidelines on the use of intravenous immune globulin for neurologic conditions. Transfus Med Rev 2007;21(suppl 1):S57-S107.

10 Group APIIE. Consensus recommendations for the use of immunoglobulin replacement therapy in immune deficiency. 2009. http:// www.info4pi.org/Documents/Publications/ APIIEG\%20Consensus\%20Recommenda tions\%20Edition\%202\%20July\%202009_ 20120201_170745.pdf (accessed September 21, 2012)

11 Immune Deficiency Foundation: Treatment experiences and preferences of patients with primary immune deficiency diseases: First national survey. 2003; http://primaryimmune. org/idf-survey-research-center/idf-surveys (accessed February 28, 2012).

12 Itkin YM, Trujillo TC: Intravenous immunoglobulin-associated acute renal failure: case series and literature review. Pharmacotherapy $2005 ; 25: 886-892$.

13 Williams AK, Ward LG, Bhatt VK: IVIG use in renal insufficiency or transplantation. US Pharm 2010;35:HS19-HS25.

14 Cayco AV, Perazella MA, Hayslett JP: Renal insufficiency after intravenous immune globulin therapy: a report of two cases and an analysis of the literature. J Am Soc Nephrol 1997; 8:1788-1794.

15 Chapman SA, Gilkerson KL, Davin TD, Pritzker MR: Acute renal failure and intravenous immune globulin: occurs with sucrose-stabilized, but not with D-sorbitol-stabilized, formulation. Ann Pharmacother 2004;38:20592067.

16 Shah S, Vervan M: Use of intravenous immune globulin and occurrence of associated acute renal failure and thrombosis. Am J Health Syst Pharm 2005;62:720-725.

17 Center for Biologics Evaluation and Research: Dear Doctor Letter: Important Drug Warning - Acute Renal Failure Associated with Immune Globulin Intravenous (Human). Bethesda, US FDA, 1999.

18 Moulis G, Sailler L, Sommet A, LapeyreMestre M, Montastruc JL: Exposure to inhibitors of the renin-angiotensin system is a major independent risk factor for acute renal failure induced by sucrose-containing intravenous immunoglobulins: a case-control study. Pharmacoepidemiol Drug Saf 2012;21:314-319.

19 Siegel J: IVIG medication safety: a stepwise guide to product selection and use. Pharmacy Practice News, Special Edition, October 2011.

20 Centers for Disease Control and Prevention: Renal insufficiency and failure associated with immune globulin intravenous therapy United States, 1985-1998. MMWR 1999;48: 518-521.

21 Orbach H, Tishler M, Shoenfeld Y: Intravenous immunoglobulin and the kidney - a two-edged sword. Semin Arthritis Rheum 2004;34:593-601.

22 Lin RY, Rodriguez-Baez G, Bhargave GA, Lin $\mathrm{H}$ : Intravenous gammaglobulin-associated renal impairment reported to the FDA: 20042009. Clin Nephrol 2011;76:365-372.

23 US Department of Health and Human Services: Analysis of supply, distribution, demand, and access issues associated with immune globulin intravenous (IGIV). 2007. http://aspe.hhs.gov/sp/reports/2007/IGIV/ report.pdf (accessed May 31, 2012).

24 Robert P: IVIG/SCIG: Global Usage Trends 2011.

25 Schulz G: Markets, milestones, perspectives. 2006. http://www.more-ir.de/download/com panies/biotest/Other\%20Information/ biotest_060320_schulz.pdf (accessed May 31, 2012).

26 Agence Française de Sécurité Sanitaire des Produits de Santé. Commission Nationale de Pharmacovigilance, 2006.
27 Haskin JA, Warner DJ, Blank DU: Acute renal failure after large doses of intravenous immune globulin. Ann Pharmacother 1999;33: 800-803.

-28 Ahsan N: Intravenous immunoglobulin-induced nephropathy: a complication of IVIG therapy. J Nephrol 1998;11:157-161.

29 Cantu TG, Hoehn-Saric EW, Burgess KM, Racusen L, Scheel PJ: Acute renal failure associated with immunoglobulin therapy. Am J Kidney Dis 1995;25:228-234.

30 Graumann A, Zawada ET Jr: Case report: acute renal failure after administering intravenous immunoglobulin. Postgrad Med 2010; 122:142-147.

-31 Laidlaw S, Bainton R, Wilkie M, Makris M: Acute renal failure in acquired haemophilia following the use of high-dose intravenous immunoglobulin. Haemophilia 1999;5:270272.

32 Rault R, Piraino B, Johnston JR, Oral A: Pulmonary and renal toxicity of intravenous immunoglobulin. Clin Nephrol 1991;36: 83-86.

33 Donataccio M, Dalle Ore G, Donataccio D Acute renal failure following intravenous administration of hepatitis B immunoglobulin in liver transplantation. Minerva Gastroenterol Dietol 2009;55:501-504.

34 Hansen-Schmidt S, Silomon J, Keller F: Osmotic nephrosis due to high-dose immunoglobulin therapy containing sucrose (but not with glycine) in a patient with immunoglobulin A nephritis. Am J Kidney Dis 1996;28: 451-453.

35 Chacko B, John GT, Balakrishnan N, Kirubakaran MG, Jacob CK: Osmotic nephropathy resulting from maltose-based intravenous immunoglobulin therapy. Ren Fail 2006;28: 193-195.

36 Horn J, Thon V, Bartonkova D, et al: Anti-IgA antibodies in common variable immunodeficiency (CVID): diagnostic workup and therapeutic strategy. Clin Immunol 2007;122:156162.

37 Kwan TH, Tong MK, Siu YP, et al: Acute renal failure related to intravenous immunoglobulin infusion in an elderly woman. Hong Kong Med J 2005; 11:45-49.

38 Lee YC, Woodfield DG, Douglas R: Clinical usage of intravenous immunoglobulins in Auckland. NZ Med J 1998;111:48-50.

39 Metallidis S, Papaioannou M, Bokolas G, Kollaras P, Gogou V, Nikolaidis P: Acute renal failure following intravenous immunoglobulin therapy in a HIV-infected patient. Clin Nephrol 2009;71:196-197.

40 Pasatiempo AM, Kroser JA, Rudnick M, Hoffman BI: Acute renal failure after intravenous immunoglobulin therapy. J Rheumatol 1994;21:347-349.

41 Tufan F, Kamali S, Erer B, et al: Safety of highdose intravenous immunoglobulin in systemic autoimmune diseases. Clin Rheumatol 2007;26:1913-1915. 
42 Villarreal IR, Ortega O, Vigil A, et al: HenochSchönlein nephritis. Adverse effect of treatment with intravenous immunoglobulin. Nephrol Dial Transplant 1999;14:795-797.

43 Tanaka H, Waga S, Tateyama T, Sugimoto K, Kakizaki Y, Yokoyama M: Acute tubulointerstitial nephritis following intravenous immunoglobulin therapy in a male infant with minimal-change nephrotic syndrome. Tohoku J Exp Med 1999;189:155-161.

44 Dickenmann M, Oettl T, Mihatsch MJ: Osmotic nephrosis: acute kidney injury with accumulation of proximal tubular lysosomes due to administration of exogenous solutes. Am J Kidney Dis 2008;51:491-503.

$\checkmark 45$ Dorman HR, Sondheimer JH, Cadnapaphornchai P: Mannitol-induced acute renal failure. Medicine (Baltimore) 1990;69:153-159.

-46 Akhtar I, Bastani B: Acute renal failure and myocarditis associated with intravenous immunoglobulin therapy. Ann Intern Med 2003; 139:W65.

47 Michail S, Nakopoulou L, Stavrianopoulos I, et al: Acute renal failure associated with immunoglobulin administration. Nephrol Dial Transplant 1997;12:1497-1499.

48 Welles CC, Tambra S, Lafayette RA: Hemoglobinuria and acute kidney injury requiring hemodialysis following intravenous immunoglobulin infusion. Am J Kidney Dis 2010; 55:148-151.

49 Arunabh-Arunabh S, Kumar G, Avila V: Acute renal failure induced by intravenous immune globulin. Am Fam Physician 1996; 53:862-865.

50 Blanco R, Gonzalez-Gay MA, Ibanez D, Sanchez-Andrade A, Gonzalez-Vela C: Paradoxi$\mathrm{cal}$ and persistent renal impairment in $\mathrm{He}$ noch-Schönlein purpura after high-dose immunoglobulin therapy. Nephron 1997;76: 247-248.

-51 Harden PN, Robertson S, Isles CG, Rodger RS: Post-transplantation renal impairment and intravenous immunoglobulin. Nephrol Dial Transplant 1996;11:1896.

-52 Ng SK: Intravenous immunoglobulin infusion causing pseudohyponatremia. Lupus 1999;8:488-490.

53 Poullin P, Moulin B, Ollier J, Benaicha M, Olmer M, Gabriel B: Renal complications from intravenous immunoglobulins. Role of renal hemodynamic factors (in French). Presse Med 1995;24:441-444.

- 54 Soares SM, Sethi S: Impairment of renal function after intravenous immunoglobulin. Nephrol Dial Transplant 2006;21:816-817.

55 Bollee G, Anglicheau D, Loupy A, et al: Highdosage intravenous immunoglobulin-associated macrovacuoles are associated with chronic tubulointerstitial lesion worsening in renal transplant recipients. Clin J Am Soc Nephrol 2008;3:1461-1468.

56 Ochs HD, Siegel J: Stabilizers used in intravenous immunoglobulin products: a comparative review. Pharm Pract News, 2010.
57 Weser E, Sleisenger MH: Metabolism of circulating disaccharides in man and the rat. J Clin Invest 1967;46:499-505.

58 Burg MB: Coordinate regulation of organic osmolytes in renal cells. Kidney Int 1996;49: 1684-1685.

59 Burg MB, Ferraris JD, Dmitrieva NI: Cellular response to hyperosmotic stresses. Physiol Rev 2007;87:1441-1474.

60 Steffgen J, Kampfer K, Grupp C, Langenberg C, Muller GA, Grunewald RW: Osmoregulation of aldose reductase and sorbitol dehydrogenase in cultivated interstitial cells of rat renal inner medulla. Nephrol Dial Transplant 2003;18:2255-2261.

61 Agence Française de Sécurité Sanitaire des Produits de Santé: Notice: Dénomination du médicament. Clairyg $50 \mathrm{mg} / \mathrm{ml}$, solution pour perfusion Immunoglobuline humaine normale (IgIV). 2011;http://afssaps-prd.afssaps.fr/ php/ecodex/notice/N0187072.htm (accessed January 4, 2012).

62 Visweswaran P, Massin EK, Dubose TD Jr: Mannitol-induced acute renal failure. J Am Soc Nephrol 1997;8:1028-1033.

63 Weaver A, Sica DA: Mannitol-induced acute renal failure. Nephron 1987;45:233-235.

64 Nissenson AR, Weston RE, Kleeman CR Mannitol. West J Med 1979;131:277-284.

65 Goldwasser P, Fotino S: Acute renal failure following massive mannitol infusion. Appropriate response of tubuloglomerular feedback? Arch Intern Med 1984;144:2214-2216.

66 Whelan TV, Bacon ME, Madden M, Patel TG, Handy R: Acute renal failure associated with mannitol intoxication. Report of a case. Arch Intern Med 1984;144:2053-2055.

67 Berard R, Whittemore B, Scuccimarri R: Hemolytic anemia following intravenous immunoglobulin therapy in patients treated for Kawasaki disease: a report of 4 cases. Pediatr Rheumatol 2012;10:10.

68 Daw Z, Padmore R, Neurath D, et al: Hemolytic transfusion reactions after administration of intravenous immune (gamma)globulin: a case series analysis. Transfusion 2008; 48:1598-1601.

69 Kahwaji J, Barker E, Pepkowitz S, et al: Acute hemolysis after high-dose intravenous immunoglobulin therapy in highly HLA sensitized patients. Clin J Am Soc Nephrol 2009;4:19931997.

70 European Medicines Agency. Privigen: Procedural steps taken and scientific information after authorisation. 2012. http://www.ema. europa.eu/docs/en_GB/document_library/ EPAR_-_Procedural_steps_taken_and_ scientific_information_after_authorisation/ human/000831/WC500043299.pdf (accessed June 5, 2012).
71 CSL Behring. Privigen: Summary of product characteristics. 2012. http://www.ema.europa. eu/docs/en_GB/document_library/EPAR_-_ Product_Information/human/000831/ WC500043077.pdf (accessed June 5, 2012).

72 CSL Behring. Public communication: Health Canada endorsed important safety information on Privigen, immune globulin intravenous (human). 2012. http://www.hc-sc.gc.ca/ dhp-mps/alt_formats/pdf/medeff/advisoriesavis/public/2012/privigen_pc-cp-eng.pdf (accessed June 5, 2012).

73 Cheng MJ, Christmas C: Special considerations with the use of intravenous immunoglobulin in older persons. Drugs Aging 2011; 28:729-736.

74 Gardulf A, Nicolay U, Asensio O, et al: Rapid subcutaneous IgG replacement therapy is effective and safe in children and adults with primary immunodeficiencies - a prospective, multi-national study. J Clin Immunol 2006; 26:77-185.

75 Ochs HD, Gupta S, Kiessling P, Nicolay U, Berger M: Safety and efficacy of self-administered subcutaneous immunoglobulin in patients with primary immunodeficiency diseases. J Clin Immunol 2006;26:265-273.

76 Moulis G, Sailler L, Montastruc JL: Reply to the commentary by Onuigbo on the article 'Exposure to inhibitors of the renin-angiotensin system is a major independent risk factor for acute renal failure induced by sucrose-containing intravenous immunoglobulins. A case-control study'. Pharmacoepidemiol Drug Saf 2012;21:900-901.

77 Onuigbo MA: Exposure to inhibitors of the renin-angiotensin system is a major independent risk factor for acute renal failure induced by sucrose containing intravenous immunoglobulins. A case-control study. Pharmacoepidemiol Drug Saf 2012;21:320-322.

-78 Cherin P, Cabane J: Relevant criteria for selecting an intravenous immunoglobulin preparation for clinical use. BioDrugs 2010;24: 211-223.

79 Tonnellier M, Guidet B: Immunoglobulines en reanimation. 1999. http://www.sfar.org/acta/ dossier/archives/ca99/html/ca99_40/99_40. htm\#74694 (accessed June 1, 2012).

80 Prescribing information: Clairyg $50 \mathrm{mg} / \mathrm{ml} \mathrm{so-}$ lution pour perfusion. http://www.looksante. $\mathrm{fr} /$ medicaments-et-traitements/solution/ clairyg-50-mg-ml-solution-pour-perfusion/ (accessed June 1, 2012).

81 Ramisse F, Deramoudt FX, Szatanik M, et al: Effective prophylaxis of influenza A virus pneumonia in mice by topical passive immunotherapy with polyvalent human immunoglobulins or $\mathrm{F}\left(\mathrm{ab}^{\prime}\right)_{2}$ fragments. Clin Exp Immunol 1998;111:583-587.

-82 Sati HI, Ahya R, Watson HG: Incidence and associations of acute renal failure complicating high-dose intravenous immunoglobulin therapy. Br J Haematol 2001;113:556-557. 